\title{
Effect of Polypropylene Fibres on the Thermal Conductivity of Lightweight Foamed Concrete
}

\author{
Ashfaque Ahmed Jhatial ${ }^{1}$, Wan Inn Goh ${ }^{1 *}$, Noridah Mohamad ${ }^{1}$, U. Johnson Alengaram ${ }^{2}$ and Kim Hung Mo $^{2}$ \\ ${ }^{1}$ Jamilus Research Center, Faculty of Civil and Environmental Engineering, Universiti Tun Hussein Onn Malaysia, Batu Pahat \\ 86400, Johor, Malaysia. \\ ${ }^{2}$ Department of Civil Engineering, Faculty of Engineering, University of Malaya, 50603 Kuala Lumpur, Malaysia.
}

\begin{abstract}
With the reduction in the permanent load on the structure and excellent insulation properties, the lightweight foamed concrete is a potential thermal insulating building material to counter the urban heat island effect, which increases the temperature of urban areas due to the concentration of infrastructures constructed using conventional concrete that absorbs the solar radiation. The lightweight foamed concrete whose dry density ranges from $400 \mathrm{~kg} / \mathrm{m}^{3}$ to 1600 $\mathrm{kg} / \mathrm{m}^{3}$, has lower thermal conductivity compared to conventional concrete. But reduced density attributes to reduced compressive strength. In this study, to enhance the mechanical properties, the foamed concrete of $1600 \mathrm{~kg} / \mathrm{m}^{3}$ density is reinforced with polypropylene fibres (PP). Four percentages of PP fibres, $0 \%$ (controlled), $0.2 \%, 0.25 \%$ and $0.30 \%$ were added into the foamed concrete. The compressive strength as well as the thermal conductivity of foamed concrete reinforced with PP fibres were determined. Based upon the findings, the optimum percentage of PP was determined to be $0.20 \%$ which gave higher compressive strength while thermal conductivity of foamed concrete was observed to decrease upon addition of PP fibres. Thus, addition of PP fibres improves the thermal resistance in the foamed concrete along with enhancing the mechanical properties.
\end{abstract}

\section{Background}

Metropolitan and urban areas where conventional concrete is widely being used, faces urban heat island (UHI) effect. UHI is the phenomenon in which higher temperatures are developed in urban areas compared to the temperatures of surrounding suburban and rural areas [1]. Large surface materials such as concrete have influence on the UHI $[2,3]$. Solar radiation is absorbed by conventional concrete, which stores the heat and releases it later, that can either be during the daytime or night-time. Urban area of 1 million and above dwellers can be up to $1.3^{\circ} \mathrm{C}$ warmer than the adjacent rural areas, while in night-time this difference can be up to $12^{\circ} \mathrm{C}[4$, 5]. Foamed concrete is a solution to the raising UHI effect in urban areas.

Air bubbles, introduced by the mixing of foaming agent in foamed concrete, enables it to not only be lightweight but also achieve thermal insulating ability. Foamed concrete, being lightweight, helps in reducing the self-weight which the conventional concrete has, causing additional permanent load to the structure. The foamed concrete can be obtained in wide range of densities ranging from 400 to $1600 \mathrm{~kg} / \mathrm{m}^{3}$ [6]. The reduction in density however has a negative impact on the compressive strength, it is a fact that by reducing the density of concrete, the compressive also decreases.

Therefore, to improve the mechanical properties of foamed concrete, polypropylene (PP) fibres is used to reinforce the foamed concrete in this study. The addition of PP fibres in foamed concrete helps increase the tensile strength [7], controlling of post cracking which leads to micro-cracks, toughness and improves the deformation characteristics of the composite [8].

\section{Literature Review}

The conventional concrete is made up of mainly cement, sand, coarse aggregates and water, and the dry density ranges from $2200 \mathrm{~kg} / \mathrm{m}^{3}$ to $2600 \mathrm{~kg} / \mathrm{m}^{3}$ [9]. Although conventional concrete is widely used in applications ranging from buildings to pavements, bridges to dams, the use of coarse aggregates in concrete, tends to increase the self-weight of the concrete, ultimately putting unnecessary permanent load on the structure, while the surface of concrete absorbs more solar radiation causing the UHI. The thermal conductivity of $2400 \mathrm{~kg} / \mathrm{m}^{3}$ density concrete is $1.3 \mathrm{~W} / \mathrm{mK}$ [10], which allows the concrete to transfer heat absorbed to the interior of the building and significantly raising the energy consumption of the building.

Due to the UHI effect, people living in the cities are more exposed to thermal stress compared to surrounding rural areas. The intensity of UHI is maximum during night-time when the temperature difference between urban areas and that of rural can reach up to $10^{\circ} \mathrm{C}$ [11]. Recent study [12] revealed that not only large cities but also villages and small built-up urban areas can have

\footnotetext{
*Corresponding author: wigoh@uthm.edu.my
} 
higher temperatures than their surrounding areas, though UHI is more common in where concentration of infrastructure is. The concentration of construction and human activities in urban areas are causes to UHI along with global warming. Increase in UHI effect has significant health risk for urban dwellers [13], due to thermal stress an increase in mortality rate has been seen [14]. Therefore, thermal insulating buildings are being focused due to their resistance to heat flow which reduces the energy consumption of the building, ultimately reducing the UHI effect.

Foamed concrete has been known to construction industry for its excellent thermal properties and reduced self-weight apart from being fire-resistant and selflevelling concrete. The use of coarse aggregates is eliminated in the foamed concrete making it lightweight concrete and the reduced density helps in reducing the self-weight. Air bubbles are introduced in the form of foaming agent, which make it a porous structure and have air voids in its matrix, while producing microporous which reduce the interfacial bonding and strong plasticizing effect on the foamed concrete $[15,16]$. The thermal conductivity value for foamed concrete is lower than conventional concrete, ranging from $0.1 \mathrm{~W} / \mathrm{mK}$ for $300 \mathrm{~kg} / \mathrm{m}^{3}$ density to $0.7 \mathrm{~W} / \mathrm{mK}$ for $1600 \mathrm{~kg} / \mathrm{m}^{3}$ density $[17,18]$. The lower conductivity of heat through the foamed concrete is due to the air voids in the matrix which slows down the flow of heat by restraining the air from passing. Thermal resistance is created by the trapped air which gives the foamed concrete its excellent thermal insulating properties [17]. Although, reduction in density of foamed concrete can lower the thermal conductivity but it also reduces the compressive strength. Micro-cracks develop in concrete with curing and rapidly propagate upon applied stress resulting in low tensile strength [8]. Reduction in density also increases the micro-cracks in the foamed concrete. It has been found that $500 \mathrm{~kg} / \mathrm{m}^{3}$ density foamed concrete develops more micro-cracks than $1000 \mathrm{~kg} / \mathrm{m}^{3}$ [19, 20]. The mechanical behaviour is affected by the development of micro-cracks in foamed concrete.

To over-come cracks, the concrete is reinforced with steel bars. Though these reinforcements help in reduction in cracks but also increase the self-weight. Over the years different fibres have been used to reinforce the concrete, in replacement of steel bars. These reinforcing fibres range from synthetically organic and inorganic fibres to natural organic and inorganic fibres.

\subsection{Characteristics of Polypropylene Fibres}

Polypropylene fibres, which are thermoplastic polymers, are synthetically organic fibres which are produced when a gaseous by-product of petroleum refining, known as propylene, is polymerized. The propylene monomers are converted into long chains of polymers during polymerization. PP fibres are chemically inert, hydrophobic and stable in alkaline environment of concrete [21].

PP fibres have interestingly been used in concrete since 1960's with addition in concrete for construction of blast resistant buildings for the US Corps of Engineers [8]. Both conventional concrete and foamed concrete has seen the addition of PP fibres. A study [22] was carried out on conventional normal concrete in which PP fibres were added at $0.15 \%, 0.30 \%$ and $0.45 \%$ dosages and steel fibres at $1 \%$ and $2 \%$, based on the results it was observed that $0.15 \%$ PP fibres achieved highest compressive strength while $0.30 \%$ achieved maximum flexural strength compared to controlled sample but when steel fibres along with PP fibres were added the compressive and flexural both increased. PP fibres content of $0 \%, 0.05 \%, 0.10 \%$ and $0.15 \%$ were also added as additives in foamed concrete of $1600 \mathrm{~kg} / \mathrm{m}^{3}$ and $1800 \mathrm{~kg} / \mathrm{m}^{3}$, it resulted in $0.15 \%$ achieving higher tensile strength and interfacial adhesion between the foamed concrete and PP fibres was observed [7]. $0 \%$ to $0.5 \%$ with an increment of $0.1 \%$, PP fibres by volume have been used in lightweight concrete, which showed that $0.2 \%$ gained the highest compressive strength while lightweight foamed concrete achieved the most the tensile strength when $0.5 \%$ of PP fibres were added [23]. By adding PP fibres, it can prevent the formation of microcracks or reduce its scale owing to the crack arresting, thinning and crack bridging effect of the fibres [24].

\section{Experimental Method}

\subsection{Materials}

Ordinary Portland cement (OPC), sand which was passed through $5 \mathrm{~mm}$, water, foaming agent and PP fibres were used. The foaming agent was used to create foam in a ratio of 1:20 (1 part of foaming agent and 20 parts of water). The water-cement ratio was taken as 0.55 while the sand-cement ratio was $2: 1$. In this study the density of foamed concrete was maintained 1600 $\mathrm{kg} / \mathrm{m}^{3}$. Four different percentages of PP fibres are utilized in this study, $0 \%$ (controlled sample with no PP content), $0.20 \%, 0.25 \%$ and $0.30 \%$ of PP fibres.

\subsection{Procedure}

The work procedure began with prepared materials for every single set. OPC, sand and percentage of PP fibres were mixed together in concrete mixer. Water was added into the mixer, along with pre-foam generated by using foamed generator and mixed together with cement mortar in concrete mixer. The addition of foam was done according to BS EN 12350-6:2009 [25] which continued gradually until target density of $1600 \mathrm{~kg} / \mathrm{m}^{3}$ was achieved. Foamed concrete was formed and was poured into the mould and kept for 24 hours. 


\subsection{Experimental Test}

Compressive strength test conducted complied with BS EN 12390-3:2009 [26]. The sample size for the test was $100 \mathrm{~mm} \times 100 \mathrm{~mm} \times 100 \mathrm{~mm}$. Before conducting the test, the sample was under air curing for 28 days. 12 samples have been prepared for the test. During the test, an axial load was applied to the cube samples and increased continuously without shock at a nominal rate within the range from $0.2 \mathrm{~N} /\left(\mathrm{mm}^{2} \mathrm{~s}\right)$ to $0.4 \mathrm{~N} /\left(\mathrm{mm}^{2} \mathrm{~s}\right)$ until the cube samples could not sustain further load. The average compressive strength of each set of samples was then recorded.

According to BS EN 12664:2001 [27], the panel samples were tested for thermal conductivity using the thermal conductivity apparatus shown in fig. 1. The panel samples for the test were of $300 \mathrm{~mm}$ x $300 \mathrm{~mm}$ x $50 \mathrm{~mm}$ size. Before conducting the test, the samples underwent air curing for 28 days. 8 samples had been prepared for the thermal conductivity test. Each sample had four holes drilled into its surface with depths of 10 , 15,20 , and $30 \mathrm{~mm}$, as shown in fig. 2, to insert the thermocouples. The samples were then placed between hot and cold plates. The temperature for cold plate has been set at $18{ }^{\circ} \mathrm{C}$ and the hot plate has been kept at $40{ }^{\circ} \mathrm{C}$ to simulate the exterior temperature and interior temperature. The hot and cold plates have been covering with one layer of barrier cushion while all sides of the sample were insulated with cork sheet [28]. The temperature of the hot and cold plate was recorded every 30 minutes for 24 hours.

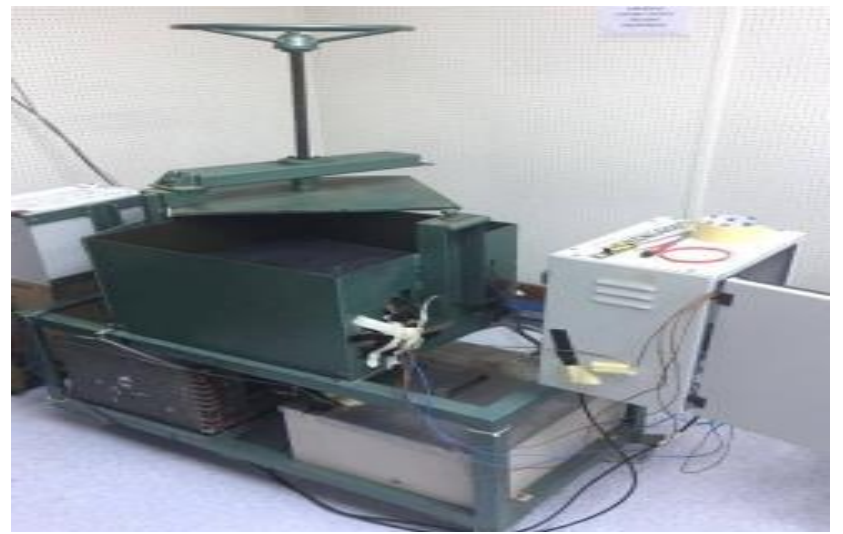

Fig. 1. Thermal Conductivity Apparatus

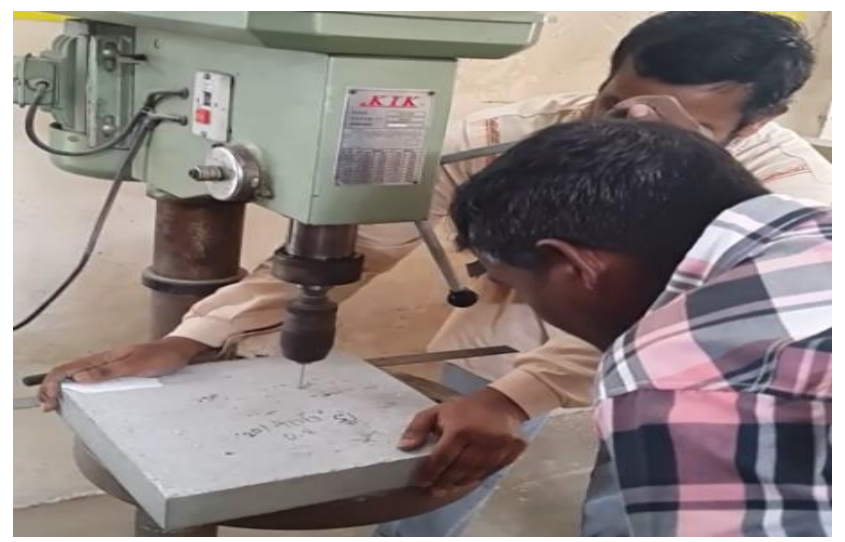

Fig. 2. Hole drilling on the surface of panels

\section{Results}

\subsection{Compressive Strength}

The results of the compressive strength test on the cubes are shown in table 1 represented graphically in fig. 3 .

Table 1. Result of Compressive Strength

\begin{tabular}{|c|c|c|}
\hline $\begin{array}{c}\text { Target } \\
\text { Density } \\
\mathbf{K g} / \mathbf{m}^{\mathbf{3}}\end{array}$ & \% of PP Fibres & $\begin{array}{c}\text { Compressive } \\
\text { Strength (MPa) }\end{array}$ \\
\hline \multirow{3}{*}{1600} & $0 \%$ & 7.459 \\
\cline { 2 - 3 } & $0.20 \%$ & 10.783 \\
\cline { 2 - 3 } & $0.25 \%$ & 9.918 \\
\cline { 2 - 3 } & $0.30 \%$ & 7.775 \\
\hline
\end{tabular}

\section{Compressive Strength of $1600 \mathrm{~kg} / \mathrm{m}^{3}$ Foamed Concrete}

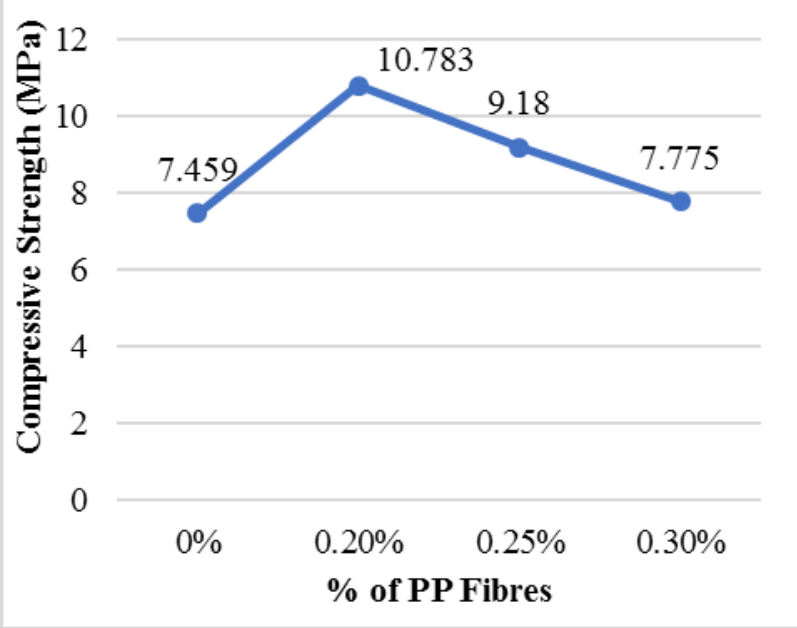

Fig. 3. Compressive Strength vs. \% of PP Fibres

From the results, it can be noted that with the addition of $0.20 \%$ of PP fibres in the foamed concrete, the compressive strength increases $44.6 \%$ compared to the controlled sample. However, with the further addition of PP fibres started to lose the compressive strength but even at $0.30 \%$ PP fibres the compressive strength was $4.23 \%$ higher than controlled sample. Foamed concrete reinforced with PP fibres achieved higher compressive strength compared to the controlled sample. This gain in strength is due to PP fibres fill up the voids which are created by air. Hence, bonding mechanism between PP fibres and the foamed concrete is achieved. However, it can also be noted that the increase in PP fibres content beyond the determined optimum dosage also reduced the compressive strength. This may be due to PP fibres being hydrophobic 
material, can retain water and as a result voids are created. Moreover, the amount of fibre will obstruct the void which will cause weak bonding between the matrixes. Hence, the compressive strength will decrease.

\subsection{Thermal Conductivity}

The thermal conductivity was conducted on the panels and Table 2 and fig. 4 shows the results of thermal conductivity of foamed concrete with different percentage of PP fibres.

Table 2. Result of Thermal Conductivity

\begin{tabular}{|c|c|c|}
\hline $\begin{array}{c}\text { Target } \\
\text { Density } \\
\mathbf{K g} / \mathbf{m}^{\mathbf{3}}\end{array}$ & \% of PP Fibres & $\begin{array}{c}\text { Thermal } \\
\text { Conductivity } \\
\text { (W/mK) }\end{array}$ \\
\hline \multirow{4}{*}{1600} & $0 \%$ & 0.68 \\
\cline { 2 - 3 } & $0.20 \%$ & 0.67 \\
\cline { 2 - 3 } & $0.25 \%$ & 0.71 \\
\cline { 2 - 3 } & $0.30 \%$ & 0.66 \\
\hline
\end{tabular}

\section{Thermal Conductivity of $1600 \mathrm{~kg} / \mathrm{m} 3$ Foamed Concrete}

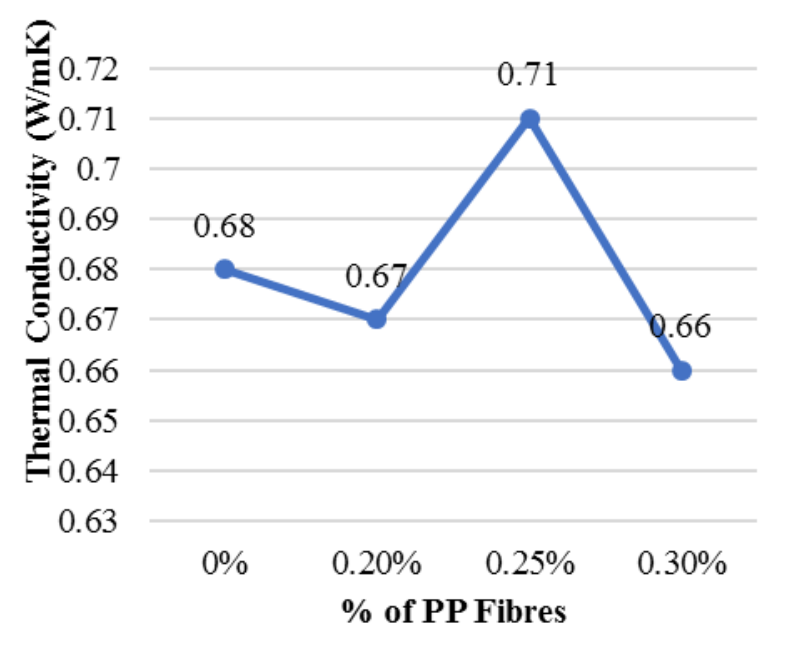

Fig. 4. Effect of PP Fibres Content on Thermal Conductivity

The addition of PP fibres in foamed concrete also had an impact on the thermal conductivity. The controlled foamed concrete sample achieved $0.68 \mathrm{~W} / \mathrm{mK}$ while when the foamed concrete was reinforced with PP fibres, it was observed that the conductivity value dropped slightly. Foamed concrete reinforced with $0.30 \%$ PP fibres exhibited $2.94 \%$ reduction in the heat flow. This is due to the characteristics of PP fibres, being, hydrophobic; hence it retains water in foamed concrete. So, when the water dried out, air pores (voids) are be formed. The more air voids in the formed concrete, the lower the thermal conductivity. So, when more PP fibres is added into foamed concrete, it will result higher percentage of porosity. Hence, the thermal conductivity will decrease when more PP fibres are added. However, the sample with $0.25 \%$ PP fibres showed higher thermal conductivity, this may be due to non-uniform distribution of PP fibres in the concrete.

\section{Conclusion}

Based on the study, it can be concluded that:

1. The optimum percentage of polypropylene fibres needed to be added in $1600 \mathrm{~kg} / \mathrm{m}^{3}$ density foamed concrete to achieve the highest compressive was $0.20 \%$.

2. The compressive strength of foamed concrete which contained polypropylene fibres achieved higher strength compared to controlled sample due to PP fibres filling in the air voids and reinforcing the concrete.

3. The thermal conductivity of foamed concrete decreased with the addition of polypropylene fibres, this is due to polypropylene fibres being hydrophobic in nature, retains water. When the water is dried out the air occupies the voids created. The more air voids the slower the transfer of heat thus lower thermal conductivity was obtained.

4. Thus, foamed concrete with the addition of polypropylene fibres can act as thermal resistance building material as with the addition of polypropylene fibres the thermal conductivity reduces as compared to the controlled sample. The addition also improves the mechanical properties of foamed concrete

The authors would like to thank the Universiti Tun Hussein Onn Malaysia (STG-528) and Research Management Centre (RMC) UTHM for the financial support for this project.

\section{References}

1. M. Santamouris, Using cool pavements as a mitigation strategy to fight urban heat island-A review of the actual developments. Renewable and Sustainable Energy Reviews, 26, pp. 224-240 (2013).

2. Y. Wang, U. Berardi and H. Akbari, Comparing the effects of Urban Heat Island Mitigation Strategies for Toronto, Canada. Energy and Buildings, (2015). 
3. M. A. Hart and D. J. Sailor, Quantifying the influence of land-use and surface characteristics on spatial variability in the urban heat island. Theoretical and Applied Climatology, 95: pp. 397-406, (2009).

4. M. Ozyavuz, B. C. Bilgili and G. Elkıran, Temperature distribution and environmental impact of Tekirdag Ataturk Forest Nature Park, Int. J. Global Warming 8(1) pp. 102-113, (2015).

5. Environmental Protection Agency (2017) Heat Island Impacts. Retrieved on June 20, 2017, from https://www.epa.gov/heat-islands

6. K. Ramamurthy, E. K. K. Nambiar and G. Indu Siva Ranjani, A classification of studies on properties of foam concrete, Cement and Concrete Composites 31(6) pp. 388-396, (2009).

7. A. R. Hazlin, Iman Afif, N. Mohamad, W. I. Goh, L. M. Sia, A. A. A. Samad and Noorwirdawati Ali, Microstructure and Tensile Strength of Foamed Concrete with Added Polypropylene Fibres. MATEC Web of Conferences 103, 01013 ISCEE 2016 (2017)

8. L. Madhavi, Swamy Raju and Deepak Mathur, Polypropylene Fibre Reinforced Concrete-A Review, International Journal of Emerging Technology and Advanced Engineering 4(4), pages 114-118 (2014).

9. A. M. Neville, Properties of Concrete, 4th ed., England: Longman (2000).

10. A. W. Hago, K. S. Al-Jabri, A. S. Al-Nuaimi and A. H. Al-Saidy, Concrete blocks for thermal insulation in hot climate. Cement and Concrete Research 35, Pg. 1472-1479, (2005).

11. D. Lauwaet, H. Hooyberghs, B. Maiheu, W. Lefebvre, G. Driesen, S. Van Looy and K. De Ridder, Detailed Urban Heat Island projections for cities worldwide: dynamical downscaling CMIP5 global climate models. Climate, 3, pp. 391-415, (2015).

12. J. Lindén, C. S. B. Grimmond and J. Esper, Urban warming in villages, Adv. Sci. Res., 12, pp. 157-162, (2015).

13. A. Lehoczky, J. A. Sobrino, D. Skoković and E. Aguilar, The Urban Heat Island Effect in the City of Valencia: A Case Study for Hot Summer Days. Urban Science, 1(1), (2017).

14. P. T. Nastos and A. Matzarakis, The effect of air temperature and human thermal indices on mortality in Athens, Greece. Theor. Appl. Climatol, 108, 591-599, (2012).

15. W. I. Goh, N. Mohamad, R. Abdullah and A. A. A. Samad, Compression test and finite element analysis of foamed concrete cube. Journal of
Engineering and Technology 5(1): pp. 1-9, (2014).

16. N. Mohamad and M. H. Mahdi, Testing of Precast Lightweight Foamed Concrete Sandwich Panel With Single and Double Symmetrical Shear Truss Connectors Under Eccentric Loading. Advanced Materials Research 335-336: pp. 1107-1116, (2011)

17. N. M. Zahari, I. A. Rahman and A. M. A. Zaidi, Foamed Concrete: Potential Application in Thermal Insulation Heat in Heat out Air- voids Foam Concrete, Proceedings of MUCEET 2009, pp. 47-52, (2009).

18. M. R. Jones and A. McCarthy, Behaviour and assessment of foamed concrete for construction application. In Use of Foamed Concrete in Construction. Dhir, R.K., Newlands, M.D., McCarthy, A., Eds.; Thomas Telford: London, UK, 61-88, (2005).

19. S. Wei, C. Yiqiang, Z. Yunsheng and M. R. Jones, Characterization and simulation of microstructure and thermal properties of foamed concrete, Construction and Building Materials, 47(10) : pp. 1278-1291, (2013).

20. D. Aldridge, Introduction to foamed concrete: what, why, how? Use of Foamed Concrete in Construction, 1-14, (2005).

21. G. Martínez-barrera, F. Ureña-nuñez, O. Gencel, and W. Brostow, Mechanical properties of polypropylene-fiber reinforced concrete after gamma irradiation, Composites Part A: Applied Science and Manufacturing, 42(5), 567-572, (2011).

22. A. K. Singh, A. Jain and D. Singh, Evaluation of Mechanical Properties for Polypropylene and Steel Fibre Reinforced Concrete. International Journal of Engineering Research \& Technology (IJERT), 2(4), pp. 1507 - 1517, (2013).

23. A. J. Hamad, Lightweight Concrete Reinforced with Polypropylene Fibres. International Journal of Advances in Applied Sciences (IJAAS) 4(2), pp. 45 - 49, (2015).

24. A. O. Mydin and S. Soleimanzadeh, Effect of polypropylene fiber content on flexural strength of lightweight foamed concrete at ambient and elevated temperatures, Advances in Applied Science Research 3(5), pp. 2837-2846. (2012).

25. BS EN 12350-6:2009, Testing fresh concrete. Density, British Standard Institution.

26. BS EN 12390-3:2009, Testing hardened concrete. Compressive strength of test specimens, British Standard Institution. 
27. BS EN 12664:2001, Thermal performance of building materials and products. Determination of thermal resistance by means of guarded hot plate and heat flow meter methods. Dry and moist products of medium and low thermal resistance, British Standard Institution.

28. U. J. Alengaram, B. A. Al Muhit, M. Z. Jumaat and M. Y. J. Liu, A comparison of the thermal conductivity of oil palm shell foamed concrete with conventional materials. Materials and Design, 51, 522-529, (2013). 